\title{
Transactions
}

\section{Pushing the limit: synthesis, photophysical and DNA binding studies of a NIR-emitting Ru(II)-polypyridyl probe with 'light switch' behaviour $\dagger$}

\author{
Robert B. P. Elmes, ${ }^{* a, b}$ Jonathan A. Kitchen, ${ }^{a, b}$ D. Clive Williams ${ }^{b, c}$ and Thorfinnur Gunnlaugsson* ${ }^{a, b}$
}

Received 4th January 2012, Accepted 3rd April 2012

DOI: $10.1039 / \mathrm{c} 2 \mathrm{dt00020b}$

The new Ru(II) polypyridyl complex 1 was synthesised using microwave irradiation from the new polypyridyl ligand 2 'DipyTAP', and its photophysical properties, and DNA binding abilities were investigated using various spectroscopic techniques; and 1 was shown to act as a 'NIR molecular light switch' for DNA with an emission window between 680 and $860 \mathrm{~nm}$.

Luminescent transition metal coordination complexes that possess DNA binding abilities have been the subject of growing interest in recent times by virtue of their potential use as DNA structure probes and cellular imaging agents. ${ }^{1,2}$ In particular, complexes such as Ru(II) and Cr(III)-polypyridyl complexes have been intensively studied owing to their tuneable photophysical and photochemical properties, which are governed by the nature of the polypyridyl ligands employed. ${ }^{3}$ Moreover, complexes that function as molecular "light switches" for DNA, i.e. being nonluminescent in aqueous media but intensely luminescent upon binding to DNA, hold particular potential as biological imaging agents. ${ }^{4,5}$ However, most Ru(II)-polypyridyl complexes suffer from short wavelength absorption, with the metal-to-ligand charge transfer (MLCT) absorption maximum being shorter than $500 \mathrm{~nm}$, and MLCT centred emission, usually shorter than $650 \mathrm{~nm}$; a drawback for biological applications and for their potential use as cancer photo-therapeutics. ${ }^{6,7}$ Recently, we have initiated a research programme into the development of new polypyridyl ligands for application in biology, ${ }^{8}$ and we have developed several examples that have been used in Ru(II)-polypyridyl complexes, as DNA targeting binders and imaging agents. ${ }^{9}$ We have also employed these for conjugation to gold nanoparticles, ${ }^{10}$ and have shown them to be excellent luminescent imaging probes, and formed mixed-lanthanide ( $\mathrm{Yb}$ (III) and $\mathrm{Nd}(\mathrm{III})$ ) transition-metal ( $\mathrm{f}-\mathrm{d}$ ) cyclen- $\mathrm{Ru}(\mathrm{II})$ complexes as dual visible- and near-infrared (NIR)-emitting DNA sensors. ${ }^{11}$ With the view of developing this area even further, we have set out to generate novel polypyridyl ligands that could be used to generate

${ }^{a}$ School of Chemistry, Centre for Synthesis and Chemical Biology, Trinity College Dublin, Dublin 2, Ireland. E-mail:

elmesr@tcd.ie,gunnlaut@tcd.ie; Tel:+35318963459

${ }^{b}$ Trinity College Biomedical Sciences Institute, Dublin 2, Ireland ${ }^{c}$ School of Biochemistry and Immunology, Trinity College, Dublin 2, Ireland.E-mail: clive.williams@tcd.ie

$\dagger$ Electronic supplementary information (ESI) available: Characterisation and figures. CCDC 859051 (2). For ESI and crystallographic data in CIF or other electronic format see DOI: $10.1039 / \mathrm{c} 2 \mathrm{dt} 00020 \mathrm{~b}$ long-wavelength excitation and emitting complexes. Inspired by the work of Meyer et al. and Zhou et al. who have recently developed a number of Ru(II)-polypyridyl complexes which exhibit ${ }^{1}$ MLCT absorbance maxima as long as $550 \mathrm{~nm}$ and a singlet oxygen quantum yield as high as $0.43,{ }^{12}$ we set out to develop $\mathbf{1}$ based on $\mathbf{2}$, a new polypyridyl ligand, which we have named 'DipyTAP' as it contains two well established polypyridyl ligands within a single structure. We foresaw that through the use of a delocalized $\pi$-system the ${ }^{1}$ MLCT absorption of 1 may be shifted to longer wavelengths as has been reported by Zhou et al. Herein, we show that the inclusion of ligand $\mathbf{2}$ in the $\mathrm{Ru}(\mathrm{II})$ polypyridyl complex $1\left[\mathrm{Ru}(\text { phen })_{2}(\text { DipyTAP })\right]^{2+}$, results in a $\sim 100 \mathrm{~nm}$ red shift of the MLCT absorption in aqueous solution in comparison to its parent complex $\left[\mathrm{Ru}(\mathrm{phen})_{3}\right]^{2+}$. Moreover, we observe that the ${ }^{3}$ MLCT emission is fully quenched in aqueous media, similar to that seen for $\left[\mathrm{Ru}(\mathrm{phen})_{2}(\mathrm{dppz})\right]^{2+}$ and related structures, ${ }^{13,14}$ but upon interaction of 1 with DNA the quenching process is perturbed resulting in an increase in the observed luminescence. To the best of our knowledge this is the first example of a Ru(II)-polypyridyl complex that can both act as a light switch for DNA, absorbing between 500 and $600 \mathrm{~nm}$; emitting at long wavelengths within the NIR region, with an emission window between 700 and $850 \mathrm{~nm}$; of significant importance, particularly for applications in imaging and photo-therapy. ${ }^{2,6,10}$

The synthesis of the Ru(II) complex $\mathbf{1}$ and that of the ligand DipyTAP, 2 is shown in Scheme 1. The synthesis of $\mathbf{2}$ was achieved by condensation of 5,6-diaminoquinoxaline, ${ }^{8} \mathbf{3}$ with 2,2'-dipyridil, $\mathbf{4}$ by reflux in EtOH yielding $\mathbf{2}$ as a beige solid in $92 \%$ yield. Crystals suitable for X-ray diffraction analysis were grown by recrystallisation from hot $\mathrm{EtOH}$, and the structure of DipyTAP is shown in Scheme 1.+ Subsequent reaction of 2 with $\mathrm{Ru}$ (phen) ${ }_{2} \mathrm{Cl}_{2}$ for $40 \mathrm{~min}$ under microwave radiation, followed

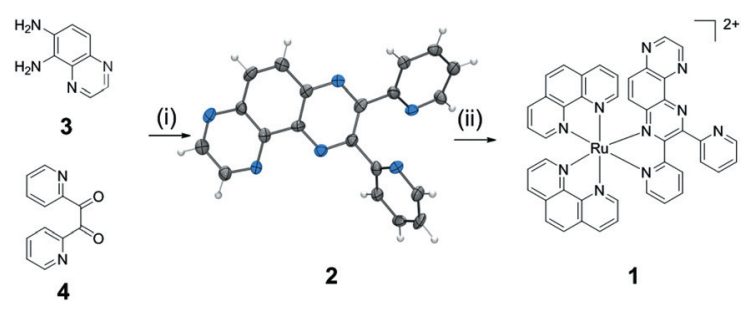

Scheme 1 Synthesis of ligand 2 and complex 1 including the X-ray crystal structure of 2. (i) EtOH, $\Delta$; (ii) $\mathrm{Ru}(\text { phen })_{2} \mathrm{Cl}_{2}, \mathrm{EtOH}: \mathrm{H}_{2} \mathrm{O}, \Delta$. 
by precipitation from $\mathrm{H}_{2} \mathrm{O}$ using excess $\mathrm{NH}_{4} \mathrm{PF}_{6}$, yielded $\mathbf{1}$, which was further purified by column chromatography using silica (eluent: $40: 4: 1 \quad \mathrm{CH}_{3} \mathrm{CN} / \mathrm{H}_{2} \mathrm{O} / \mathrm{NaNO}_{3}$-(sat), giving 1 in $42 \%$ yield. The complex was fully characterised (see ESI $\dagger$ ); the ${ }^{1} \mathrm{H}$ NMR is shown in Fig. 1, while MALDI HRMS gave $m / z=399.0763$ for the $\mathrm{M}^{2+}$ ion, where the observed isotopic distribution pattern matched that of the calculated one (see ESI $\uparrow$ ).

The $\mathrm{Cl}^{-}$salt of 1 was reformed by stirring the $\mathrm{PF}_{6}{ }^{-}$form in Amberlite resin $\left(\mathrm{Cl}^{-}\right.$form $)$and was found to be fully soluble in both aqueous solution and many organic solvents. The characteristic absorption spectra of $\mathbf{1}$ and $\mathbf{2}$ together with the excitation and emission spectra of $\mathbf{1}$ in $\mathrm{MeCN}$ are shown in Fig. 2. The absorption spectrum of 2 showed $\lambda_{\max }$ at 220 and $305 \mathrm{~nm}$ whereas 1 had characteristic transitions at ca. 220, 262, 295, 370,420 and at $535 \mathrm{~nm}$. The absorbance spectra were also measured in $\mathrm{MeOH}$, EtOH, acetone and $\mathrm{CH}_{2} \mathrm{Cl}_{2}$, however, very little variation was observed between these solvents.

In $\mathrm{pH} 7.4$ phosphate buffered aqueous solution the absorbance spectrum remained largely unchanged where the band at $262 \mathrm{~nm}$ ( $\varepsilon=71900 \mathrm{~cm}^{-1} \mathrm{M}^{-1}$ ) was characteristic of $\pi-\pi^{*}$ transitions of the ancillary phen ligands while the band at $295 \mathrm{~nm}$ ( $\varepsilon=36700 \mathrm{~cm}^{-1} \mathrm{M}^{-1}$ ) was attributed to $\pi-\pi^{*}$ transitions localised on ligand 2 . The less intense band at $370 \mathrm{~nm}$ ( $\varepsilon=20700 \mathrm{~cm}^{-1} \mathrm{M}^{-1}$ ) was attributed to transitions within the phenazine part of the ligand, while the transitions at $420 \mathrm{~nm}$ $\left(\varepsilon=9950 \mathrm{~cm}^{-1} \mathrm{M}^{-1}\right)$ and $545 \mathrm{~nm}\left(\varepsilon=8600 \mathrm{~cm}^{-1} \mathrm{M}^{-1}\right)$ were characteristic of MLCT transitions from the Ru(II) centre. Interestingly the latter MLCT band at $545 \mathrm{~nm}$ was seen to be red shifted by $\sim 10 \mathrm{~nm}$ in comparison to that in organic solutions suggesting a stabilisation of the MLCT state in aqueous media.

Upon excitation into each of the absorbance maxima, luminescence was observed at long wavelength, which when recorded in aerated $\mathrm{MeOH}, \mathrm{EtOH}$, acetone and $\mathrm{MeCN}$ solution, within an

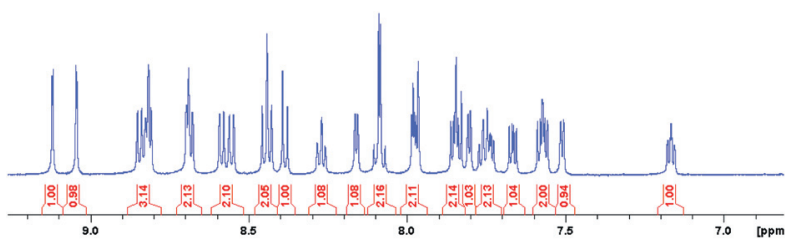

Fig. 1 The ${ }^{1} \mathrm{H}$ NMR spectra of $1\left(600 \mathrm{MHz}, \mathrm{CD}_{3} \mathrm{CN}\right)$.

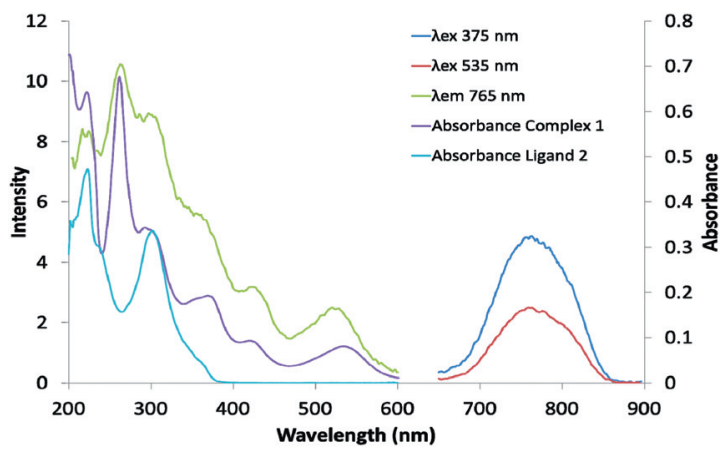

Fig. 2 The UV/Visible absorption spectra the excitation $\left(\lambda_{\mathrm{em}}=\right.$ $765 \mathrm{~nm})$ and emission spectra $\left(\lambda_{\mathrm{ex}}=370 \mathrm{~nm}\right.$ and $\left.535 \mathrm{~nm}\right)$ of $1(10 \mu \mathrm{M})$ in $\mathrm{MeCN}$. emission window of $c a .200 \mathrm{~nm}$, with a $\lambda_{\max }$ at $c a .765 \mathrm{~nm}$. While in $\mathrm{CH}_{2} \mathrm{Cl}_{2}$, the $\lambda_{\max }$ was blue shifted, occurring at ca. $720 \mathrm{~nm}$, for which a quantum yield of luminescence of $\Phi_{\mathrm{F}}<0.001$ was determined, no significant changes were seen in degassed solution, except for a slight increase in $\Phi_{\mathrm{F}}$. Similarly, the excitation of 1 (either at 765 or $720 \mathrm{~nm}$ ) yielded emission spectra that were structurally identical to the absorption spectra in the same solvents (Fig. 2). As had been anticipated, no significant MLCT based emission was detected from $\mathbf{1}$ in aqueous solution suggesting a quenching pathway caused by the polar protic solvent as previously been seen for dppz based $\mathrm{Ru}(\mathrm{II})$ complexes, which are structurally related to $1 .{ }^{13}$ However, as such complexes are also known to give rise to large emission enhancements upon binding to DNA, ${ }^{14}$ we next investigated the ability of $\mathbf{1}$ to bind to DNA to assess its suitability as a potential luminescence 'switch on' probe.

Considering the positively charged nature and the propensity of $\mathrm{Ru}(\mathrm{II})$ complexes to bind to DNA, ${ }^{7,9-11}$ we expected $\mathbf{1}$ to interact with DNA through a combination of electrostatic and $\pi$-stacking or groove binding interactions, which typically results in changes in their electronic spectra. To determine the binding affinity of $\mathbf{1}$ for DNA, a series of DNA titrations were carried out with salmon testes DNA (stDNA) at pH 7.4 (10 mM phosphate buffer), using absorption and emission spectroscopy. As can be seen the absorption spectrum, Fig. 3, was significantly affected, in particular, the MLCT centred transition at $536 \mathrm{~nm}$ underwent a $27 \%$ hypochromism as well as being red shifted to $545 \mathrm{~nm}$. Unfortunately, we were unable to determine accurately $\Phi_{\mathrm{F}}$ but it was found to be $<0.001$. Moreover, such changes were found to be only marginally affected by increasing $\mathrm{NaCl}$ concentration whereby $70 \%$ of the complex remained bound to DNA even after the addition of $300 \mathrm{mM} \mathrm{NaCl}$ (see ESI $\dagger$ ). This suggests that although electrostatic interactions were prominent in the binding of 1 to stDNA, this was not the sole mode of interaction. From these UV/Vis absorption titrations we were able to determine the binding affinity of $\mathbf{1}$ for stDNA, by fitting the above changes in the MLCT absorption using the method of McGhee and Von Hippel. ${ }^{15}$ This gave the binding constant $K_{\mathrm{b}}$ as $3.2 \times 10^{4} \mathrm{M}^{-1}( \pm 0.12)$ (average of several titrations) with a binding site size of $n=7.05( \pm 0.23)$. Concomitantly, the emission spectrum of $\mathbf{1}$ was greatly affected upon binding of $\mathbf{1}$ to

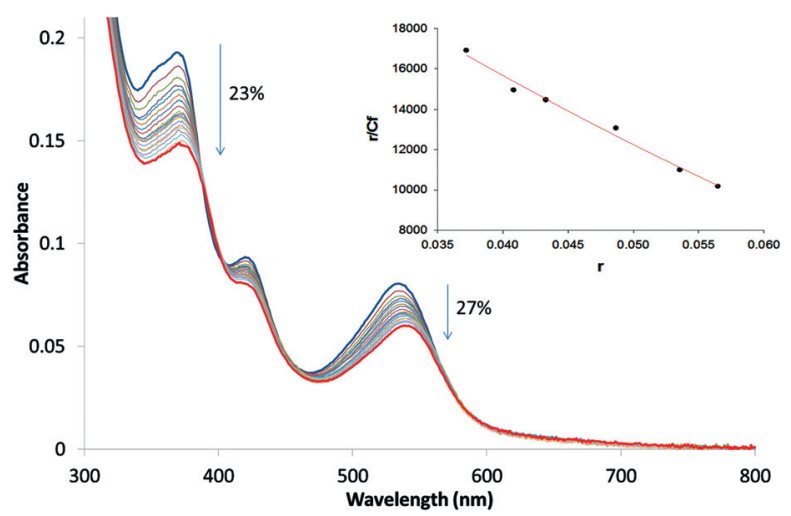

Fig. 3 Changes in the absorption spectrum of $\mathbf{1}(9.4 \mu \mathrm{M})$ with increasing concentration of stDNA $(0-670 \mu \mathrm{M})$. Inset: The fit of the changes in the MLCT band using the McGhee and Von Hippel equation. 


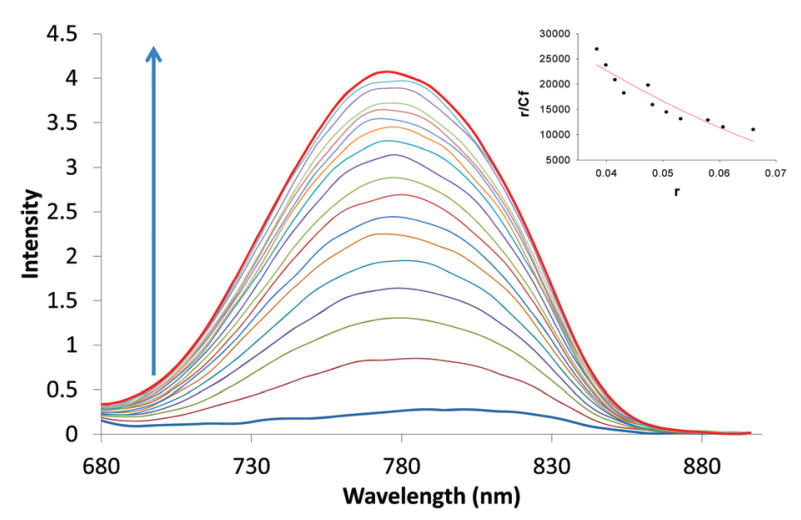

Fig. 4 Changes in the luminescence emission spectrum of $1(9.4 \mu \mathrm{M})$ with increasing concentration of stDNA $(0-670 \mu \mathrm{M})\left(\lambda_{\text {ex }} 545 \mathrm{~nm}\right)$. The blue and the red spectra indicate the beginning and the end point of the titrations. Inset: The fit of the changes in the MLCT band using the McGhee and Von Hippel equation.

stDNA where, in particular, the MLCT centred emission, occurring within the window of 680-860 nm, was 'switched on' with an excess of two order of magnitude enhancement as demonstrated in Fig. 4. This enhancement was accompanied by a blue shift of $c a .20 \mathrm{~nm}$ (see Fig. 4) from $c a .800 \mathrm{~nm}$ to $780 \mathrm{~nm}$ for the fully bound complex. Similar effects were seen in the emission spectrum upon excitation at other wavelengths such as $420 \mathrm{~nm}$ and $370 \mathrm{~nm}$. Again, analysis of these binding interactions by fitting the changes in the emission spectra using the above binding model of McGhee and Von Hippel, gave $K_{\mathrm{b}}=5.3 \times 10^{4} \mathrm{M}^{-1}( \pm 0.58)$ and a binding site size of $n=8.0$ $( \pm 0.56)$, which is consistent with the results seen in the absorption spectra above. While this binding affinity is somewhat smaller than that reported for dppz based ligands, ${ }^{14}$ it is an order of magnitude greater than has been reported for $\mathrm{Ru}\left[\mathrm{phen}_{3}\right]^{2+}$ (50 mM NaCI, $5 \mathrm{mM}$ Tris, $\mathrm{pH}$ 7.5). ${ }^{16}$ These results clearly demonstrate the advantage of using $\mathbf{2}$ to push the absorption and emission wavelengths towards the NIR regions; suggesting that the lowest lying MLCT excited state is centred on the Ru-2 part of 1 .

Thermal denaturation experiments further supported the interaction of 1 with DNA (see ESI $\dagger$ ) where 1 was found to stabilise the double stranded DNA at both high and medium loading $\left(\mathrm{P} / \mathrm{D}=10\right.$ or 25 , respectively, with a $\Delta T_{\mathrm{m}}=3.1^{\circ} \mathrm{C}$ at higher $\mathrm{P} / \mathrm{D}$ loading). The affinity of $\mathbf{1}$ for stDNA was also confirmed by carrying out an ethidium bromide (EtBr) displacement assay (see ESI $\dagger) ;{ }^{17}$ which demonstrated that 1 effectively displaced $\mathrm{EtBr}$ from the DNA helix with an apparent binding constant $\left(K_{\text {app }}\right)$ of $\sim 10^{5} \mathrm{M}^{-1}$. Furthermore, changes were evident in both the circular dichroism (CD) and the linear dichroism (LD) spectrum of $\mathbf{1}$ for the binding of the complex to DNA. For the former, structural changes in the signature CD of DNA were observed while in the LD, the evolutions of a positive signal occurred across the entire absorption of $\mathbf{1}$ in $10 \mathrm{mM}$ phosphate buffer, at $\mathrm{pH} 7.4$ ( $\operatorname{stDNA}=150 \mu \mathrm{M}$, see ESI $\dagger$ ). The observation of a positive LD signal between 300 and $500 \mathrm{~nm}$, as a function of decreasing P/D values, implies that these transitions are oriented parallel to the alignment of the helix axis in solution. Hence, these results support a binding mode in which the complex is edgewise

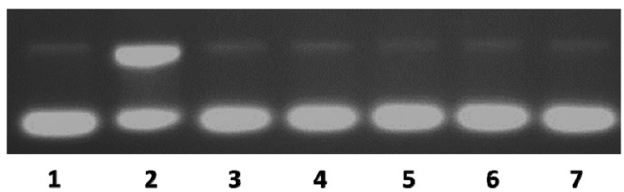

Fig. 5 Agarose gel electrophoresis of pBR322 DNA $\left(1 \mathrm{mg} \mathrm{ml}^{-1}\right)$ after $30 \mathrm{~min}$ irradiation $\left(2 \mathrm{~J} \mathrm{~cm}^{-2}\right)$ in $10 \mathrm{mM} \mathrm{pH} 7.4$ phosphate buffer; lane 1: plasmid DNA control; lane 2: $\left[\mathrm{Ru}(\mathrm{bpy})_{3}\right]^{2+}(\mathrm{P} / \mathrm{D} 5)$; lane 3 and 4: 1 $(\mathrm{P} / \mathrm{D}$ 10, 5); lane 5: 1 in the dark (P/D 5); lanes 6 and 7: $1+10 \mathrm{mM}$ $\mathrm{NaN}_{3}(\mathrm{P} / \mathrm{D} 10,5)$.

inserted into the grooves of $\mathrm{DNA}^{18}$ but may also be partiallyintercalating through the ancillary phen ligands as has recently been demonstrated for $\left[\operatorname{Ru}(\mathrm{TAP})_{2}(\mathrm{dppz})\right]^{2+} \cdot{ }^{19}$ Given the structure of $\mathbf{1}$, such a binding mode is not unexpected and further work is on-going in order to fully quantify this binding behaviour.

In order to further evaluate $\mathbf{1}$ as a potential biological imaging tool we also set out to evaluate any phototoxicity that might result from the photo excitation of $\mathbf{1}$ using Agarose gel electrophoresis of pBR322 plasmid DNA. As shown in Fig. 5 when incubated in the dark 1 showed no measurable DNA cleavage. Similarly, after $30 \mathrm{~min}$ of irradiation (using $400 \mathrm{~nm}$ cut off filter and $2 \mathrm{~J} \mathrm{~cm}^{-1}$ ), under aerobic conditions at a $\mathrm{P} / \mathrm{D}$ ratio of 5 and 10, 1 showed no photo cleavage effects, demonstrating its inability to cause DNA damage under light irradiation. Similarly, in the presence of $\mathrm{NaN}_{3}$, a singlet oxygen scavenger, $\mathbf{1}$ also showed no photo-cleavage efficiency. As a control, the same pBR322 supercoiled DNA was treated with the known ${ }^{1} \mathrm{O}_{2}$ sensitizer $\left[\mathrm{Ru}(\mathrm{bpy})_{3}\right]^{2+}$ which resulted in $\mathrm{ca}$. $60 \%$ DNA photocleavage.

In summary, we have developed a novel ligand $\mathbf{2}$, which was characterised fully using X-ray crystallography, and the corresponding $\mathrm{Ru}(\mathrm{II})$ polypyridyl complex $\mathbf{1}$. The complex was shown to absorb at long wavelength and emit within an emission window of $c a .200 \mathrm{~nm}$, between 680 and $860 \mathrm{~nm}$ in buffered aqueous solution upon binding to DNA; whereby the emission of 1 was 'switched on'. We are currently further investigating the nature of the DNA interactions of $\mathbf{1}$, as well as undertaking the synthesis of related structures, where various functional groups are being incorporated into $\mathbf{1}$, with a view to achieving greater $\Phi_{\mathrm{F}}$ values, longer absorption and emission wavelengths to evaluate their application as luminescent probes and in vivo imaging agents.

\section{Acknowledgements}

We thank Science Foundation Ireland (SFI PI Award 2010, and SFI RFP Awards 2008 and 2009), and The Irish Research Council for Science, Engineering \& Technology (IRCSET) (Postdoctoral Fellowship to JAK, Postgraduate Fellowship to RBPE) for financial support, and Dr John E. O'Brian and Dr Martin Feeney for helping out with NMR and MS, respectively.

\section{Notes and references}

$\$$ Crystal data: $\mathrm{C}_{20} \mathrm{H}_{12} \mathrm{~N}_{6}(2), M=978.92$, monoclinic, $a=15.066(3)$, $\dot{b}=7.0000(14), c=15.541(3) \AA, \beta=107.45(3)^{\circ}, V=1563.6(5) \AA^{\sharp}$, 
$T=115(2) \mathrm{K}$, space group $P 2_{1} / n, Z=4,10976$ reflections measured, 2528 unique $\left(R_{\text {int }}=0.1038\right)$ which were used in all calculations. Final $\mathrm{w} R_{2}=0.3629$ (all data) and $R_{1}=0.1357(I>2 \sigma)$. CCDC 859051 .

1 C. Metcalfe and J. A. Thomas, Chem. Soc. Rev., 2003, 32, 215.

2 (a) Q. Zhao, C. Huanga and F. Li, Chem. Soc. Rev., 2011, 40, 2508; (b) V. Fernandez-Moreira, F. L. Thorp-Greenwood and M. P. Coogan, Chem. Commun., 2010, 46, 186.

3 (a) J. G. Vos and J. M. Kelly, Dalton Trans., 2006, 4869; (b) M. Wojdyla, J. A. Smith, S. Vasudevan, S. J. Quinn and J. M. Kelly, Photochem. Photobiol. Sci., 2010, 9, 1196.

4 (a) B. M. Zeglis, V. C. Pierre and J. K. Barton, Chem. Commun., 2007, 4565; (b) C. A. Puckett and J. K. Barton, Bioorg. Med. Chem., 2010, 18, 3564 .

5 (a) C. A. Puckett, R. J. Ernst and J. K. Barton, Dalton Trans., 2010, 39, 1159; (b) C. A. Puckett and J. K. Barton, J. Am. Chem. Soc., 2007, 129, 46.

6 U. Schatzschneider, Eur. J. Inorg. Chem., 2010, 1451.

7 (a) M. R. Gill, J. Garcia-Lara, S. J. Foster, C. Smythe, G. Battaglia and J. A. Thomas, Nat. Chem., 2009, 1, 662; (b) M. R. Gill, H. Derrat, C. G. W. Smythe, G. Battaglia and J. A. Thomas, ChemBioChem, 2011, 12, 877; (c) A. Ghosh, P. Das, M. R. Gill, P. Kar, M. G. Walker, J. A. Thomas and A. Das, Chem.-Eur. J., 2011, 17, 2089; (d) A. Ghosh, A. Mandoli, D. K. Kumar, N. S. Yadav, T. Ghosh, B. Jha, J. A. Thomas and A. Das, Dalton Trans., 2009, 9312; (e) L. Cosgrave, M. Devocelle, R. J. Forster and T. E. Keyes, Chem. Commun., 2010, 46, 103.
8 R. B. P. Elmes, M. Erby, S. M. Cloonan, S. J. Quinn, D. C. Williams and T. Gunnlaugsson, Chem. Commun., 2011, 47, 686.

9 (a) R. B. P. Elmes, M. Erby, S. A. Bright, D. C. Williams and T. Gunnlaugsson, Chem. Commun., 2012, 48, 2588; (b) G. J. Ryan, S. Quinn and T. Gunnlaugsson, Inorg. Chem., 2008, 47, 401.

10 R. B. P. Elmes, K. N. Orange, S. M. Cloonan, D. C. Williams and T. Gunnlaugsson, J. Am. Chem. Soc., 2011, 133, 15862.

11 A. M. Nonat, S. J. Quinn and T. Gunnlaugsson, Inorg. Chem., 2009, 48, 4646.

12 (a) Q.-X. Zhou, W.-H. Lei, J.-R. Chen, C. Li, Y.-J. Hou, X.-S. Wang and B.-W. Zhang, Chem.-Eur. J., 2010, 16, 3157; (b) J. A. Treadway, G. F. Strouse, R. R. Ruminski and T. J. Meyer, Inorg. Chem., 2001, 40, 4508.

13 A. W. McKinley, P. Lincoln and E. M. Tuite, Coord. Chem. Rev., 2011, 255, 2676.

14 A. E. Friedman, J. C. Chambron, J. P. Sauvage, N. J. Turro and J. K. Barton, J. Am. Chem. Soc., 1990, 112, 4960.

15 J. D. McGhee and P. H. V. Hippel, J. Mol. Biol., 1974, 86, 469.

16 A. M. Pyle, J. P. Rehmann, R. Meshoyrer, C. V. Kumar, N. J. Turro and J. K. Barton, J. Am. Chem. Soc., 1989, 111, 3051.

17 D. L. Boger, B. E. Fink, S. R. Brunette, W. C. Tse and M. P. Hedrick, J. Am. Chem. Soc., 2001, 123, 5878.

18 (a) B. Nordén, J. Mol. Recognit., 1994, 7, 141; (b) P. Lincoln and B. Norden, J. Phys. Chem. B, 1998, 102, 9583.

19 J. P. Hall, K. O'Sullivan, A. Naseer, J. A. Smith, J. M. Kelly and C. J. Cardin, Proc. Natl. Acad. Sci. U. S. A., 2011, 108, 17610. 